\title{
Live-attenuated influenza virus vaccine reduces virus shedding of newborn piglets in the presence of maternal antibody
}

\section{Marika Genzow \\ Christa Goodell \\ Troy J. Kaiser \\ Wesley Johnson \\ Marc Eichmeyer}

\section{Video Abstract}

Keywords: influenza, influenza A virus, flu, piglets, LAIV, maternally derived antibodies, virus shedding, swine, pigs, respiratory disease, passive immunity, H1N1, H3N2, intranasal vaccination, vaccine, vaccination, killed vaccine, live attenuated vaccine, Boehringer Ingelheim Animal Health, Influenza and Other Respiratory Viruses

Posted Date: September 20th, 2019

DOI: https://doi.org/10.21203/rs.2.15070/v1

License: (9) This work is licensed under a Creative Commons Attribution 4.0 International License. Read Full License 


\section{Abstract}

A new vaccine against influenza virus may offer previously unattainable levels of protection to newborn pigs. Just as humans muddle through the flu season each year, pigs across the globe are affected by their own regular outbreaks, causing notable economic losses in the pork industry. But an international research team has now shown that the newly developed vaccine can keep the virus from replicating in newborn pigs, potentially reducing the spread of disease. Historically, breeding females have been the main target for influenza control in pig populations. Females given a vaccine containing an inactive form of influenza type A virus - a key agent of respiratory disease in pigs - can confer passive immunity to their offspring. But this doesn't stop piglets from becoming infected with or passing on the virus - it just keeps them from showing clinical signs for a short period, since any maternally derived protection will wear off over time. The new vaccine also targets influenza type A virus but differs from past control strategies in two important ways. First, it's a live attenuated virus specially engineered to work against two common flu strains - H1N2 and H3N2. Second, it's given directly to newborn piglets by intra-nasal administration, avoiding the reliance on maternal protection. The new formulation was tested in newborn piglets that were either vaccinated or given saline as a control. Several weeks later, the piglets were infected with virus strains that genetically differed from the vaccine. The viruses caused body temperature to spike in all the animals, indicating the successful start of an infection. But the vaccine reduced the severity of the piglets' clinical signs compared to the control group. More importantly, the vaccine also impacted viral replication. It not only reduced the number of pigs that shed virus, but also the overall duration of shedding. This trend held true regardless of whether the piglets' mothers were vaccinated, showing that the vaccine stimulated an immune response in the piglets despite the presence of maternal antibodies. Although more studies are needed to determine how to best integrate the new vaccine into current animal management practices, these findings suggest it's a promising option for defending pigs against influenza $\mathrm{A}$. 